\title{
Multimodal Construction Grammar issues are Construction Grammar issues
}

\begin{abstract}
If multimodal work in terms of Construction Grammar is still rare nowadays, this is not just because the upsurge of multimodality in linguistics in general is rather recent. Attempts to include nonverbal layers of expression (especially gesture) in Construction Grammar have uncovered a number of theoretical issues that need to be reflected upon before any serious claims on the existence of multimodal constructions can be made. While some scholars take these issues as reasons for leaving the non-verbal outside of the scope of Construction Grammar, this paper shows that several of these issues are not actually related to multimodality, but rather hint at more general theoretical issues in Construction Grammar. Hence, it is argued that these issues should be seen as an incentive for rethinking and refining the notion of 'construction', rather than as a reason for leaving multimodality aside.
\end{abstract}

Keywords: Construction Grammar, multimodality, gesture

\section{Introduction}

Recent years have witnessed a considerable growth of the field of gesture studies, including linguistic accounts of gesture. This turn towards gesture and other non-verbal layers of expression (posture, prosody etc.) has not only led to a growing amount of studies on how these non-verbal modalities interact with speech in constructing and conveying meaning: it necessarily also stimulated the theoretical discussion about how to describe non-verbal units from a linguistic perspective and to what extent existing frameworks and paradigms can be extended to include non-verbal and multimodal patterns.

One of the frameworks that has been mentioned repeatedly in this discussion is Construction Grammar (CxG). Several scholars, including Langacker (2008: 15) and Deppermann (2006: 61), have hinted at the possibility of extending the scope of $\mathrm{CxG}$ to include non-verbal layers of expression and to consider multimodal patterns (i.e. patterns involving, for instance, speech and gesture) as constructions in the same way as the purely monomodal-verbal patterns CxG has traditionally been looking at, and there are indeed scholars who have already proposed analyses in terms of multimodal CxG (e.g. Andrén 2014, Schoonjans et al. 2015, Zima 2013).

However, while the idea of including gestures (and other non-verbal dimensions) in $\mathrm{CxG}$ may seem rather straightforward ${ }^{1}$, its implementation is not. The reason is that one may think of several arguments for not considering particular multimodal patterns (or, by extension, multimodal patterns in general) as good candidates for constructions. It is certainly true that there are some issues to be remedied before one can assume that there may indeed be such a thing as a multimodal construction. However, as I will try to show in this paper, these issues are not linked to the multimodal extension of $\mathrm{CxG}$ as such; rather, they are inherent to CxG itself, but their true impact only shows up if one goes beyond the scope of traditional $\mathrm{CxG}$ research and tries to include non-verbal units. Hence, to the extent that monomodalverbal $\mathrm{CxG}$ has not yet found ways of dealing with them, these issues should not be used as arguments against a multimodal extension of $\mathrm{CxG}$, but rather as an incentive to rethink and refine particular elements of $\mathrm{CxG}$ theory. This will be illustrated in the following for six partly interrelated topics: recurrence and level of granularity (Section 2), frequency (Section 3), scope and temporal discrepancy (Section 4), and the cognitive reality of the constructions (Section 5). ${ }^{2}$

In this paper, the issues will be discussed mainly by referring to gesture. It should be clear, though, that gesture is not the only non-verbal layer that can be included into multimodal CxG. However, the

\footnotetext{
${ }^{1}$ For arguments in terms of the usage-based model see Schoonjans et al. (2015), Zima (2014), and Zima \& Bergs (this issue), among others.

${ }^{2}$ A question that will not be discussed here is to what extent non-verbal behavior is organized according to a grammar and could thus be described in terms of CxG. Not only has Fricke (2012) already shown what a grammar of gesture could look like, the question is also of lesser relevance for this paper, as I am here looking at multimodal structures in which the verbal and the non-verbal interact. The verbal layer is organized according to a grammar, and the question at stake here is whether non-verbal elements interacting with this verbal layer in multimodal structures can be integrated into that grammar, irrespective of whether there is such a thing as a grammar of gesture in general.
} 
issues are largely the same with layers such as posture and facial expression, so the discussion in the following can mutatis mutandis be extended to cover these other non-verbal layers as well.

\section{Recurrence and level of granularity}

Strictly speaking, $\mathrm{CxG}$ is not just one paradigm but rather a cluster of related paradigms. What unites these paradigms is the fact that they consider the basic unit of language to be what is called a 'construction', i.e. a symbolic pairing of form and meaning. It is also assumed that patterns that occur just once do not surpass the level of the constructs (i.e., the concrete instantiations); to be considered as a real construction, a pattern has to show a certain frequency or recurrence. Langacker (2001: 146), for instance, claims that in Cognitive Grammar, "any aspect of a usage event [...] is capable of emerging as a linguistic unit, should it be a recurrent commonality" (emphasis added), and Goldberg (2006: 5) refers to "sufficient frequency" in her definition of "construction'. The question at which point a pattern is frequent or recurrent enough to be a construction will be discussed in the next section; at this point, the question to be dealt with is how to determine if a pattern is recurrent at all.

In the debate about multimodal $\mathrm{CxG}$, the main question in this respect is how to decide upon recurrence in gesture. While it is certainly true that a considerable amount of gestures is produced $a d$ hoc (what Müller 2010: 39 calls 'singular gestures'), gesture scholars have already indicated that recurrence patterns in gesture can be found. In line with Müller (2010), one may even distinguish two kinds of recurrent gesture patterns (although the line may not always be that easy to draw): 'recurrent gestures' in the strict sense of the term (see also Ladewig 2014) and 'emblems', the difference being that the latter are less dependent on the particular usage context for their meaning while the former typically are closely related to the verbal utterance they co-occur with.

But how can we determine whether a gesture is recurrent? Indeed, as Harrison (2009: 82) already stated, "no two tokens of a gesture are ever identical." However, the same also holds true for purely verbal forms: as Stetter (2005) points out on several occasions referring to Goodman's work, the type is "nothing but a group of sufficiently similar copies" (Stetter 2005: 127, my translation and emphasis). The type is thus an abstraction over individual tokens that resemble each other but are "never identical" (Stetter 2005: 281, my translation). Hence, following Harrison (2009: 82), we can assume that individual gesture tokens are slightly different while still belonging to the same gesture type. Mutatis mutandis, the same holds true at the level of constructs (tokens) and constructions (types), be they mono- or multimodal. Hence, the recurrence issue does not just play a role at the level of gesture, as monomodal $\mathrm{CxG}$ also has to abstract away over the idiosyncrasies of the individual constructs. In other words, it mainly is a matter of the level of abstraction.

Similarly, one may wonder whether it has to be the entire gesture (i.e. the type) that is recurrent in order for the pattern to be a multimodal construction. Just as it is possible to have half-open slots in verbal constructions, which can be filled by different elements sharing particular features, it is possible that the slot for the gesture in a multimodal construction is only defined by particular features and thus allows for all gestures displaying these features to occur in it. As an example, think of Zima's (2013) analysis of constructions such as [ $\mathrm{V}$ (motion) in circles], which are accompanied by a circular movement of the hand. What counts, is that the movement is circular, but the other form features of the gesture (orientation, handshape etc.) can show variation. Similarly, in Sambre and Brône's (2013) work on gestures with verbs of cutting and breaking in Dutch, the relevant gesture is an iconic representation of the action described verbally. In this case, there is not even a particular form feature that is constant over all attestations; it is only the meaning that determines whether the gesture fits into the construction. Hence, it is possible to find recurrent commonalities at a very abstract level: rather than a particular gesture as such, it is the relevant gesture features that have to be recurrent in order to have a good candidate for a multimodal construction.

The fact that sometimes the recurrence is only found at the level of gesture features and not at the level of the gesture itself need not be an argument against including gesture in $\mathrm{CxG}$, though. At the verbal level as well, the slots of a construction can be defined in a very abstract way. Think of constructions such as the Ditransitive Construction or the Caused-Motion Construction (e.g. Goldberg 1995). In these cases, the individual slots are not filled in by the same (verbal) elements each time either. Rather, they are defined in abstract terms (e.g. 'animate NP'), and all words or phrases to which this definition applies can occur in the slot. Hence, the fact that it is not always possible to find a particular 
gesture that recurs in exactly the same form is not an argument against multimodal $\mathrm{CxG}$; it is mainly a matter of finding the right level of granularity or abstraction - just like in studies in monomodal CxG.

\section{Frequency}

After this discussion of how the idea of recurrence can be applied to gesture, the next question is how to decide whether a multimodal pattern is sufficiently recurrent to be considered as a construction. In other words, how frequently should a gesture pattern co-occur with a verbal pattern to make them form a multimodal construction?

In the case of gestures, this is an interesting question, given that $100 \%$ co-occurrence is highly unlikely to ever occur, the reason being that external factors such as the holding of an object or the performing of an action while speaking are more likely to influence our gesturing behavior (and perhaps even suppress all gestures) than our speech. But even taking these situational factors into account, the amount of cases without co-occurrence is considerable. In her work on multimodal motion constructions in English, for instance, Zima (2013, see also Schoonjans \& Zima 2014) found co-occurrence rates reaching up to $85.94 \%$, and Sambre \& Brône's (2013) highest rate in their work on cutting and breaking verbs in Dutch is $82.2 \%$. A natural question then is whether these rates are not too low to truly count as multimodal constructions.

While the question how CxG can or should deal with such rates that are clearly below $100 \%$ goes beyond the scope of this paper (see e.g. Schoonjans \& Zima 2014), one also has to ask to what extent such pure frequency rates can be used as an argument against including gesture in CxG. Actually, the answer already comes from monomodal CxG, with Traugott and Trousdale (2013: 11) stating that "“sufficient frequency' is not operationalizable" as a criterion to decide upon construction status. Strictly speaking, asking from which frequency onwards a pattern is recurrent enough to be a construction boils down to asking for a kind of base rate. However, to the best of my knowledge, no such base rate has ever been proposed in $\mathrm{CxG}$, be it mono- or multimodal. It would not make sense to do so either, as monomodal constructions show variation as well. An increasing number of scholars takes the view that constructions are prototype structures with more and less prototypical instantiations (e.g. Gries 2003, Barth-Weingarten 2006, Imo 2007a, Ziem \& Lasch 2011) or that they can contain optional elements (e.g. Imo 2007b). ${ }^{3}$ Hence, the assumption that a multimodal pattern cannot be a construction because the verbal element sometimes occurs with another gesture or with no gesture at all is hard to uphold if one does accept variation at the purely verbal level. The question thus mainly is how much variation should be allowed, but this is a question that scholars in monomodal $\mathrm{CxG}$ have to deal with as well.

Furthermore, the discussion thus far is based on relative frequencies only, but how about absolute frequencies? What if a multimodal co-occurrence pattern is relatively rare in relative frequencies (compared to the absolute frequency of, say, the verbal element), yet still it has a considerable absolute frequency and thus (following e.g. Goldberg 2006) would merit to be considered as a (multimodal) construction in its own right, next to the purely verbal construction? Here as well, "'sufficient frequency' is not operationalizable", as it is not clear what the base rate in absolute frequency would be for a pattern to be a construction, not even in monomodal CxG.

Given these difficulties in operationalizing frequency, an increasing number of scholars in monomodal $\mathrm{CxG}$ turn away from the use of mere frequencies (be they relative or absolute) in uncovering constructional patterns and also look at salience and how typical certain elements are for particular contexts/constructions, for instance by using statistical methods such as collostructional strength (see e.g. Gries 2016 for an overview). While multimodal collostructional analysis is still virgin territory, it does not seem to be excluded to develop these techniques further so they can also be applied to multimodal data (see also Hoffmann, this issue). This would allow to get a better idea of the strength of a multimodal pattern and its status as a multimodal construction, but multimodal co-occurrence analysis and the statistics used in it simply are not advanced enough yet to make this possible.

Summing up, the role of frequency in $\mathrm{CxG}$ as a whole, i.e. both monomodal and multimodal $\mathrm{CxG}$, remains rather vague and has to be thought through more thoroughly. Therefore, although it is very well possible that less common multimodal patterns should not be considered as instantiations of a multimodal construction, frequency issues should not be used as an argument in the discussion on

\footnotetext{
${ }^{3}$ Think as well of Imo's (2007a: 37) remark that the realization of constructions is often "fragmented".
} 
multimodal $\mathrm{CxG}$ as the role of frequency in monomodal $\mathrm{CxG}$ (and its interaction with factors such as the salience of particular instantiation types) is not clear either. A way around this could be to further develop statistical techniques from monomodal $\mathrm{CxG}$ (such as collostruction analysis) to make them applicable to multimodal data. Until we know what this brings, we cannot refer to it in arguing for or against a multimodal $\mathrm{CxG}$, as it may very well be that this will offer some good evidence for the constructional status of multimodal patterns which as such are not all that frequent. Hence, it seems that the frequency issue can be circumvented in a similar way as in monomodal $\mathrm{CxG}$, once again making this argument void when arguing against multimodal $\mathrm{CxG}$.

\section{Scope and temporal discrepancy}

A further issue is the fact that a verbal element and the accompanying gesture do not always coincide neatly. This is a well-known fact in gesture studies: the so-called preparation phase of the gesture takes place before pronouncing the verbal element in order to make sure that the so-called stroke phase (i.e. the meaningful part of the gesture) is realized at the same time as the verbal element (McNeill 2005: 35). However, this is just a tendency, as there are also cases in which the gesture is realized entirely before or entirely after the verbal element. This is a peculiarity of gesture, and it is also influenced by external factors similar to the ones playing a role in the non-realization of a gesture (cf. Section 3 ). While there seems to be some reluctance to accept particular multimodal patterns as constructions (or even to accept the idea of multimodal $\mathrm{CxG}$ as a whole) because of such temporal discrepancies, I am not aware of any convincing arguments to reject the idea of a multimodal construction on the basis of temporal discrepancies. $^{4}$

Furthermore, note that the lack of neat temporal coincidence is actually functional in some cases. Indeed, especially for gestures with pragmatic meanings, their spreading (i.e. the words they co-occur with) may be an indication of their scope, as Harrison (2010) and Schoonjans (2014) have shown for gestures of negation and downtoning, respectively. Hence, these gestures do not just go with a verbal marker of negation or downtoning, but rather extend over all elements falling under the scope of the negation or the downtoning. This temporal discrepancy may cause some reluctance in thinking of these patterns as multimodal constructions, yet again, in my view, this has not been argued in a convincing way, especially since in this case, there is a functional explanation of the discrepancy. Scope marking as such is functional in language (think of particular prosodic patterns, for instance), yet while it is possible to hold a gesture while pronouncing a sentence to indicate its scope, it is not possible to hold the pronunciation of a word while uttering other words falling under its scope. This explains why there is a discrepancy at the level of form, but at the meaning level (taking 'meaning' in its broadest sense to include scope), there is no discrepancy, as the scope of the downtoning or negating gesture corresponds to the scope of the verbal downtoner or negation.

Again, this actually takes us to an issue of CxG in general. As Ziem \& Lasch (2011: 279) have pointed out, $\mathrm{CxG}$ has focused too much on form in determining what counts as a construction, while meaning has received less attention. However, if a construction is thought of as a pairing of form and meaning, elements of meaning - including scope - should also be taken into account in determining the 'size' of a construction. An example of this would be Meer's (2012) analysis of constructions with the downtoning particle $j a$ in German, in which she does not just consider the particle as a construction, but rather proposes to think of highly schematic constructions covering the entire scope of the particle (often an entire clause), with the particle itself being the only specified lexical element in the construction. Defining the constructions in this way means that actually, there is no temporal discrepancy at all given the corresponding scope, even if the timing of the verbal and non-verbal elements is not identical. Hence, the temporal discrepancy is not actually a problem of multimodal $\mathrm{CxG}$; it should rather be seen as an incentive to rethink the way constructions are defined in general, i.e. also in monomodal $\mathrm{CxG}$.

\footnotetext{
${ }^{4}$ On a side-note, recall that some scholars have proposed the idea of discontinuous constructions in monomodalverbal CxG (e.g. Müller 2016). This is not much different from multimodal patterns where the verbal and gestural part do not coincide: in both cases, the construction consists of two non-adjacent parts, just that they are both verbal in the former case while one is gestural in the latter.
} 


\section{Cognitive reality}

Another question that is sometimes raised by opponents of multimodal $\mathrm{CxG}$ is how to prove the mental reality of multimodal constructions. Indeed, it is assumed in several branches of $\mathrm{CxG}$ that constructions are stored as cognitive units and hence that the constructions described should be psychologically real (e.g. Deppermann 2006: 51, Fischer \& Stefanowitsch 2007: 13). However, how can we be sure that a recurrent multimodal pattern is indeed stored in our brains as a multimodal construction rather than as a multimodal co-occurrence pattern of in se non-multimodal constructions? Indeed, a general assumption in $\mathrm{CxG}$ is that each construction is stored together with information about how and in which contexts it is typically used (e.g. Auer 2006, Deppermann 2007: 116, Fried \& Östman 2004: 21, cf. also Östman's 2015 idea of a Construction Discourse), so it would be imaginable to think that part of this usage information of a verbal construction is that it regularly co-occurs with a particular gestural pattern that may be considered as a separate, gestural construction, but without considering this co-occurrence as such as a truly multimodal construction (cf. Schoonjans's (2014) idea of a semi-multimodal notion of 'construction').

While it is undeniably true that the cognitive reality of particular multimodal constructions, or even of the phenomenon 'multimodal construction' per se, is hard to prove, the same is also true for monomodal constructions. Deppermann's (2006: 55) question of what counts as one construction and the aforementioned related issue of how much variation constructions allow illustrates this question: How can one be sure that a pattern is stored separately as a construction and should not be considered as a variant of another pattern? The same is also true for the issue of 'sufficient frequency': From which frequency onwards can we assume that a structure is stored separately? Actually, we can even take this one step further and ask the question how we can be sure that the language patterns in our brains are actually the constructions we are describing, i.e. whether any of the (also monomodal) constructions described so far are actually cognitively real (cf. e.g. Lieven 2009). Despite all research in psycho- and neurolinguistics, we still have no way yet of undeniably proving this, and it is unclear whether we will ever be able to do so. At best, we can come up with indirect evidence, for instance by means of elicitation tasks such as the one proposed by Perek \& Goldberg (2015) - and I do not see why, given the right methodology, this would be excluded as a way of working in multimodal $\mathrm{CxG}$ to get at least such indirect evidence. Such indirect evidence can lead construction grammarians to come up with plausible assumptions and good candidates of what counts as a construction, and it is not clear why this would not be an equally valid way of working in multimodal $\mathrm{CxG}$, even if it is only indirect evidence that does not really prove the cognitive reality of these structures. Hence, the lack of proof of cognitive reality cannot be used as an argument against multimodal $\mathrm{CxG}$ in particular, given that it is no less of an issue for monomodal $\mathrm{CxG}$ (even though it is not addressed in many $\mathrm{CxG}$ studies) and that it is possible to do $\mathrm{CxG}$ research nevertheless.

\section{Conclusion}

On the basis of the issues raised above, it should be clear that the nature of multimodal constructions is still a much-debated question. However, as I have tried to show in this paper, this uncertainty about the position of multimodality in $\mathrm{CxG}$ should not be used as an argument for rejecting the possibility of multimodal constructions per se. Rather, it can be explained in part by the rather young age of multimodal research in CxG: we simply need more research to get a better view on the situation. However, an even more important reason is that several issues of multimodal $\mathrm{CxG}$ actually boil down to questions that traditional, monomodal-verbal $\mathrm{CxG}$ has to deal with as well. The six issues discussed in this paper (recurrence and level of granularity, frequency, scope and temporal discrepancy, and the cognitive reality of the constructions) do not represent an exhaustive overview; further questions that are still unanswered for both mono- and multimodal $\mathrm{CxG}$ include how to deal with ad-hoc recurrences (cf. Brône \& Zima's 2014 idea of 'ad-hoc constructions') and how the relations between constructions and the structure of the constructicon should be conceptualized - especially in view of the relation between mono- and multimodal constructions (cf. Imo's [2015: 71] claim regarding construction taxonomies that "as of now it is still unclear how such a taxonomic network of constructions should be conceptualized").

To be sure, this entire discussion should not be seen as an argument against $\mathrm{CxG}$ - only against the view that multimodality has no place in $\mathrm{CxG}$. Indeed, note that several core tenets of $\mathrm{CxG}$ have not been 
discussed as somehow problematic for the inclusion of non-verbal layers of expression (for instance the basic notion of a construction as a form-meaning pairing, the non-modularity of the linguistic system, and the non-derivational nature of the framework - see e.g. Auer 2006 and Deppermann 2006, 2007). $\mathrm{CxG}$ definitely has its merits, for instance precisely by assuming that the language system is nonmodular and that more specific instantiations of a more abstract pattern can actually exist as separate constructions next to the more abstract construction (e.g. Goldberg 2006), and monomodal CxG has actually already proposed ways of dealing with some of the issues mentioned (e.g. half-open slots for the recurrence issue, increased attention for meaning/scope in the case of temporal discrepancy). These solutions can be extended to multimodality, making that the issues should not be used as arguments against a multimodal $\mathrm{CxG}$. But also other issues, such as the cognitive reality of constructions, are not just restricted to multimodal CxG: they have thus far not received a final answer in theorizing about monomodal-verbal $\mathrm{CxG}$ either. Hence, these issues should not be used as arguments against including multimodality in $\mathrm{CxG}$, but rather as incentives to rethink and refine ideas about $\mathrm{CxG}$ in general, so as to make $\mathrm{CxG}$ (also in its monomodal branches) an even better framework for the description of language.

\section{References}

Andrén, Mats. 2014. Multimodal constructions in children. Is the headshake part of language? Gesture 14(2). 141-170.

Auer, Peter. 2006. Construction Grammar meets Conversation: Einige Überlegungen am Beispiel von „so“-Konstruktionen. In Susanne Günthner \& Wolfgang Imo (eds.), Konstruktionen in der Interaktion, 291-314. Berlin: Walter de Gruyter.

Barth-Weingarten, Dagmar. 2006. Fuzzy boundaries - Überlegungen zu einer Grammatik der gesprochenen Sprache nach konversationsanalytischen Kriterien. In Arnulf Deppermann, Reinhard Fiehler \& Thomas Spranz-Fogasy (eds.), Grammatik und Interaktion, 67-96. Radolfzell: Verlag für Gesprächsforschung.

Brône, Geert \& Elisabeth Zima. 2014. Towards a dialogic construction grammar: Ad hoc routines and resonance activation. Cognitive Linguistics 25(3). 457-495.

Deppermann, Arnulf. 2006. Construction Grammar - Eine Grammatik für die Interaktion? In Arnulf Deppermann, Reinhard Fiehler \& Thomas Spranz-Fogasy (eds.), Grammatik und Interaktion. Untersuchungen zum Zusammenhang von grammatischen Strukturen und Gesprächsprozessen, 4365. Radolfzell: Verlag für Gesprächsforschung.

Deppermann, Arnulf. 2007. Grammatik und Semantik aus gesprächsanalytischer Sicht. Berlin: Walter de Gruyter.

Fischer, Kerstin \& Anatol Stefanowitsch. 2007. Konstruktionsgrammatik: Ein Überblick. In Kerstin Fischer \& Anatol Stefanowitsch (eds.), Konstruktionsgrammatik: Von der Anwendung zur Theorie, 317. Tübingen: Stauffenburg.

Fricke, Ellen. 2012. Grammatik multimodal. Wie Wörter und Gesten zusammenwirken. Berlin: Walter de Gruyter.

Fried, Mirjam \& Jan-Ola Östman. 2004. Construction Grammar: A thumbnail sketch. In Mirjam Fried \& Jan-Ola Östman (eds.), Construction Grammar in a Cross-Language Perspective, 11-86. Amsterdam: John Benjamins.

Goldberg, Adele Eva. 1995. Constructions. A Construction Grammar approach to argument structure. Chicago: University of Chicago Press.

Goldberg, Adele Eva. 2006. Constructions at Work. The nature of generalization in language. Oxford: Oxford University Press.

Gries, Stefan Thomas. 2003. Towards a corpus-based identification of prototypical instances of constructions. Annual Review of Cognitive Linguistics 1. 1-27.

Gries, Stefan Thomas. 2013. Data in Construction Grammar. In Thomas Hoffmann \& Graeme Trousdale (eds.), The Oxford Handbook of Construction Grammar, 93-108. Oxford: Oxford University Press.

Harrison, Simon Mark. 2009. Grammar, Gesture, and Cognition. The case of negation in English. Bordeaux: Université Michel de Montaigne Bordeaux 3 dissertation.

Harrison, Simon Mark. 2010. Evidence for node and scope of negation in coverbal gesture. Gesture 10(1). 29-51. 
Imo, Wolfgang. 2007a. Der Zwang zur Kategorienbildung: Probleme der Anwendung der Construction Grammar bei der Analyse gesprochener Sprache. Gesprächsforschung 8. 22-45.

Imo, Wolfgang. 2007b. Construction Grammar und Gesprochene-Sprache-Forschung. Konstruktionen mit zehn matrixsatzfähigen Verben im gesprochenen Deutsch. Tübingen: Max Niemeyer.

Imo, Wolfgang. 2015. Interactional Construction Grammar. Linguistics Vanguard 1. 69-77.

Ladewig, Silva. 2014. Recurrent gestures. In Cornelia Müller, Alan Cienki, Ellen Fricke, Silva H. Ladewig, David McNeill \& Jana Bressem (eds.), Body-Language - Communication. An international handbook on multimodality in human interaction, 1558-1574. Berlin: De Gruyter Mouton.

Langacker, Ronald W. 2001. Discourse in Cognitive Grammar. Cognitive Linguistics 12(2). 143-188.

Langacker, Ronald W. 2008. Cognitive Grammar. A basic introduction. Oxford: Oxford University Press.

Lieven, Elena. 2009. Developing constructions. Cognitive Linguistics 20(1). 191-199.

McNeill, David. 2005. Gesture \& Thought. Chicago: University of Chicago Press.

Meer, Dorothee. 2012. ,dAs is ja völliger BLÖDsinn; '- Konstruktionen der gesprochenen Sprache mit der Abtönungspartikel ja. In Björn Rothstein (ed.), Nicht-flektierende Wortarten, 89-116. Berlin: Walter de Gruyter.

Müller, Cornelia. 2010. Wie Gesten bedeuten. Eine kognitiv-linguistische und sequenzanalytische Perspektive. Sprache und Literatur 105. 37-68.

Müller, Stefan. 2016. Grammatical Theory. From transformational grammar to constraint-based approaches. Berlin: Language Science Press.

Östman, Jan-Ola. 2015. From Construction Grammar to construction Discourse....and back. In Jörg Bücker, Susanne Günthner \& Wolfgang Imo (eds.), Konstruktionsgrammatik V. Konstruktionen im Spannungsfeld von sequenziellen Mustern, kommunikativen Gattungen und Textsorten, 15-43. Tübingen: Stauffenburg.

Perek, Florent \& Adele Eva Goldberg. 2015. Generalizing beyond the input: The functions of the constructions matter. Journal of Memory and Language 84. 108-127.

Sambre, Paul \& Geert Brône. 2013. Cut and break. The multimodal expression of instrumentality and causality. Paper presented at MaMuD1, Aachen, 22 November 2013.

Schoonjans, Steven. 2014. Modalpartikeln als multimodale Konstruktionen. Eine korpusbasierte Kookkurrenzanalyse von Modalpartikeln und Gestik im Deutschen. Leuven: KU Leuven dissertation.

Schoonjans, Steven, Geert Brône \& Kurt Feyaerts. 2015. Multimodalität in der Konstruktionsgrammatik: Eine kritische Betrachtung illustriert anhand einer Gestikanalyse der Partikel einfach. In Jörg Bücker, Susanne Günthner \& Wolfgang Imo (eds.), Konstruktionsgrammatik $V$, 291-308. Tübingen: Stauffenburg.

Schoonjans, Steven \& Elisabeth Zima. 2014. The Frequency Issue in Multimodal Construction Grammar. Paper presented at ICCG 8, Osnabrück, 4 September 2014.

Stetter, Christian. 2005. System und Performanz. Symboltheoretische Grundlagen von Medientheorie und Sprachwissenschaft. Weilerswist: Velbrück.

Traugott, Elizabeth Closs \& Graeme Trousdale. 2013. Constructionalization and Constructional Changes. Oxford: Oxford University Press.

Ziem, Alexander \& Alexander Lasch. 2011. Von der geschriebenen zur gesprochenen Sprache: Quo vadis Konstruktionsgrammatik? In Alexander Lasch \& Alexander Ziem (eds.), Konstruktionsgrammatik III. Aktuelle Fragen und Lösungsansätze, 275-281. Tübingen: Stauffenburg. Zima, Elisabeth. 2013. English multimodal motion constructions. A construction grammar perspective. Studies van de BKL 8. 14-28.

Zima, Elisabeth. 2014. Gibt es multimodale Konstruktionen? Eine Studie zu englischen und deutschen Bewegungskonstruktionen. Gesprächsforschung 15. 1-48. 